\title{
APRENDIZAGEM INFORMAL NO SETOR PÚBLICO: FOCO NAS INTERAÇÓES SOCIAIS E CONTEXTO ORGANIZACIONAL
}

\author{
INFORMAL LEARNING IN THE PUBLIC SECTOR: FOCUSING ON SOCIAL \\ INTERACTIONS AND ORGANIZATIONAL CONTEXT
}

Recebido em 09.06.2016. Aprovado em 06.01.2017

Avaliado pelo sistema double blind review

DOI: http://dx.doi.org/10.12712/rpca.v11i1.775

\section{Diogo Reatto}

profdiogoreatto@hotmail.com

Universidade Presbiteriana Mackenzie (Mackenzie), São Paulo/SP, BRASIL

\section{Arilda Schmidt Godoy}

arildagodoy@gmail.com

Universidade Presbiteriana Mackenzie (Mackenzie), São Paulo/SP, BRASIL

\section{Resumo}

Este estudo qualitativo interpretativo básico visa a compreender como ocorrem as experiências de aprendizagem vivenciadas por técnicos-administrativos de uma universidade estadual paulista no local de trabalho. O referencial teórico articula a literatura de Aprendizagem Informal nos locais de trabalho com a Teoria Pragmática da Aprendizagem de Bente Elkjaer. As 16 entrevistas com servidores apontam que eles aprendem suas tarefas informalmente, por meio da experiência da prática cotidiana no local de trabalho. As interações com os mundos e submundos sociais identificados despertam emoções que ora apoiam ora suprimem a aprendizagem. Os fatores de contexto que determinam como se aprende são clima, cultura e estrutura física organizacionais, expectativas de progresso e relação entre novatos e experientes. Este trabalho avança a discussão em Aprendizagem Organizacional ao estudar o papel das interações sociais no provimento de aprendizagem a indivíduos que não ocupam função gerencial, utilizar perspectiva teórica baseada na vertente construção social e apresentar modelo explicativo de como compreender o papel das interações sociais nos processos de aprendizagem informal nos locais de trabalho.

Palavras-chave: Aprendizagem Informal. Aprendizagem no Local de Trabalho. Aprendizagem nas Organizações. Teoria da Aprendizagem Social. Serviço Público.

\section{Abstract}

This research is an interpretative and qualitative study that aims to understand how technical-administrative employees learning experiences occur in the workplace of a state and public faculty. The theoretical frame joins the literature about Informal Learning in the workplace with Social Learning Theory by Elkjaer. The 16 semi-structured interviews with technical-administrative employees show that they learn their tasks informally, by their experience and daily practice in the workplace. The employees' interactions with the social worlds and subworlds identified in the interviews evoked emotions which sometimes support and raise difficulties at times to learning. The context factors that influence informal learning are organizational climate, culture and layout, job development expectation and relationship between newcomers and experienced employees. This work advances the discussion in the field of Organizational Learning by studying the role of social interactions in the provision of organizational learning, using theoretical perspective based on social construction approach and presenting an explanatory model of how to understand the role of social interactions in informal learning processes in the workplace.

Keywords: Informal Learning. Workplace Learning. Organizational Learning. Social Learning Theory. Public Sector. 


\section{Introdução}

O mundo do trabalho tem sido tratado como um contexto singular de aprendizagem, tanto cognitivo como socialmente, no qual o indivíduo desenvolve continuamente a habilidade de aprender e socializarse (GERBER, 2006; BRANDI; ELKJAER, 2011). Por isso, suas lentes estão focadas no que as pessoas aprendem no trabalho, no uso que fazem desse aprendizado adquirido nas suas atividades diárias e quais os impactos nos colegas e na organização.

A revisão de literatura internacional sobre aprendizagem informal (denominada a partir daqui como AI) nos locais de trabalho confirma que o tema tem sido sistematicamente atestado, contrário à produção nacional que, segundo Reatto e Godoy (2015), não se revelou significativa nem em termos numéricos (apenas 21 artigos em periódicos no período 2006-2012) nem conceituais (não se preocupando em delimitar com clareza a conceituação de AI, adotando definições genéricas e cotidianas). Pesquisas no Canadá revelam que mais de $70 \%$ da aprendizagem no local de trabalho são de natureza informal (LIVINGSTONE, 2000). Os trabalhos de Eraut (2011) indicam que as atividades informais desenvolvidas no trabalho foram responsáveis por cerca de 70 a $90 \%$ daquilo que foi aprendido.

Quando se retoma a trajetória histórica sobre AI, verifica-se que muito do discurso encontrado em estudos nacionais e internacionais se volta para a educação vocacional, valorizando-se o saber-fazer, e não considera as contribuições de outros campos de conhecimento como a sociologia, psicologia cognitiva e antropologia (GARRICK, 1998). Contudo, é importante reconhecer que existem abordagens de AI que destacam a emancipação do indivíduo rumo a um aprendizado autodirigido, fruto do seu viver, da sua experiência nas atividades cotidianas (Aprendizado Vivencial/Experiencial) e das suas relações sociais (GARRICK, 1998; HAGER, 2012), até aquelas que privilegiam seu desenvolvimento no cerne corporativo, focando a aprendizagem no local de trabalho e as organizações que aprendem (GARRICK, 1998).

Assim, esta pesquisa examina e aprofunda a aprendizagem no local de trabalho como um processo que envolve a interpretação do sentido que os indivíduos dão ao seu trabalho, em que medida fatores organizacionais influenciam o contexto da aprendizagem organizacional e as consequentes formas pelas quais seus funcionários aprendem, examinando a AI como processo e não como produto/resultado de outra atividade (ERAUT, 2011). Ao articular a literatura de AI nos locais de trabalho com a teoria da aprendizagem social, tem-se que o aprender é uma prática relacional e coletiva situada no contexto particular do trabalho e que a aprendizagem é influenciada pelo ambiente no qual o trabalho ocorre (GERBER, 2006), enfatizando as aprendizagens advindas da informalidade, da improvisação e da conversação. O conhecimento é distribuído entre os indivíduos, os quais, ao aplicarem a aprendizagem, além de assumirem o papel de praticantes, tornam-se parte da organização (ELKJAER; HUYSMAN, 2008).

Para este estudo qualitativo interpretativo básico (MERRIAM,1998), apoiado no paradigma interpretacionista e no interacionismo simbólico, conduziram-se 16 entrevistas com servidores técnicoadministrativos das áreas administrativa e acadêmica de uma faculdade da área de saúde em um câmpus de uma universidade estadual paulista. $\mathrm{O}$ objetivo geral é compreender como ocorrem as experiências de aprendizagem vivenciadas por esses servidores em seus locais de trabalho.

A escolha de uma universidade pública justificase pela urgência em pesquisas sobre aprendizagem em setores não-lucrativos, pois o setor público bem como as universidades: (a) são grandes o suficiente para garantir a atenção de pesquisadores da área da Administração; (b) sofreram mudanças em sua estrutura e funções e, assim, assemelham-se às demais organizações sociais, sempre em constantes e aceleradas mutações devido ao impacto de novas tecnologias, da alta competitividade e da escassez de recursos humanos e financeiros; (c) as características específicas que influenciam a aprendizagem no setor público podem ajudar a expandir o conhecimento sobre o campo da aprendizagem organizacional em vários tipos de organização (RASHMAN et al., 2009).

Para tratar dos aspectos levantados na Introdução, este trabalho estrutura-se em quatro partes. $\mathrm{Na}$ primeira, relacionam-se os estudos sobre AI nos locais de trabalho com a Teoria Pragmática da Aprendizagem de Bente Elkjaer. $\mathrm{Na}$ segunda, explicam-se os procedimentos metodológicos usados na construção do estudo. $\mathrm{Na}$ terceira parte, são discutidos os resultados das entrevistas, o que precede as considerações finais. 


\section{Referencial Teórico}

\section{Aprendizagem Informal e no Local de Trabalho}

As primeiras revisões sobre pesquisas em AI surgiram na década de $90 \mathrm{com}$ autores como Marsick, Watkins e Garrick (MARSICK; WATKINS, 2001), os quais relacionavam o conceito de AI com termos como aprendizagem en passant, aprendizagem incidental e não formal, modelo social, aprendizagem experiencial, aprendizagem autodirigida, aprendizagem na ação, reflexão na ação, reflexão crítica, aprendizagem transformativa, conhecimento tácito, aprendizagem situada e comunidades de prática. Contudo, esses termos não são sinônimos (MARSICK; WATKINS, 2001; ANTONELLO, 2011). A AI é fundamental e normalmente motivada, direcionada e sustentada pelos próprios interesses e intenções de um indivíduo (MARSICK; YATES, 2012).

Outros autores que também discutiram a AI após a conceituação de Marsick e Watkins (2001), como Conlon (2003), Le Clus (2011) e Eraut (2004, 2011), tomam a definição de Marsick e Watkins como conceito norteador de seus trabalhos. A exemplo desses autores, Hager (2012, p. 207) argumenta que a AI "é um importante tipo de aprendizado que tem sido injustamente negligenciado pela literatura até o momento".

Dessa forma, a AI pode ser definida como toda experiência de aprendizagem que não possui um currículo específico, não há professores responsáveis pela ministração desse conteúdo, tampouco um sistema de avaliação e certificação, abrangendo, portanto, uma diversidade extraordinariamente vasta de ocasiões nas quais a aprendizagem pode se manifestar (HAGER, 2012).

Para Jacobs e Park (2013), a AI surge em situações nas quais a aprendizagem pode não ser o objetivo principal da atividade, senão iniciada por uma situação-problema que requer uma solução. A AI pode acontecer individualmente, como em estudos autodirigidos, ou em grupo, sendo que a maior parte dela não é planejada e contém algo de casualidade, de imprevisto, na sua essência.

Eraut (2004) prefere definir a aprendizagem informal como aquela que se aproxima mais de um fim informal do que formal, ou seja, a AI ocorre quando os objetivos finais da aprendizagem são informais. A AI, então, é implícita, intencional, situacional, não estruturada e sem instrutor.
O caminho para que a AI alcance horizontes mais amplos nas pesquisas e nas organizações está nas contínuas mudanças e transformações sobre o conceito de aprendizagem. Impulsionados pela economia globalizada, mudanças nos mercados e exigências crescentes de trabalhadores do conhecimento, os conceitos de trabalho e aprendizagem devem ser vistos como relacionados (BOUD; GARRICK, 1998). Por sua vez, o ambiente de trabalho tem sido gradualmente reconhecido como legítimo para a aprendizagem de novas habilidades e conhecimentos que permitam aos indivíduos uma melhor participação nas atividades do dia-a-dia, pois a AI acontece por meio das oportunidades que estão integradas nas rotinas e práticas de trabalho cotidianas (LE CLUS, 2011), e não há como separar participação no trabalho de aprendizagem (BILLET'T, 2001; HAGER, 2012).

Assim, num conceito abrangente, a aprendizagem no local de trabalho (LE CLUS, 2011, p. 357):

pode ser descrita como situada no contexto da prática social (Lave e Wanger, 1991), na qual o cenário do trabalho fornece uma oportunidade de trabalhadores adquirirem conhecimento que conectem teoria e prática de uma forma realista e eficiente (Billet, 1996). Aprendizagem no local de trabalho inclui aprendizagem baseada na experiência, aprendizagem informal e incidental (Marsick e Watkins 2001, Marsick e Volpe 1999; Foley, 1999; Hager e Halliday, 2006), aprendizagem autodirigida (Foley, 1999) bem como aprendizagem organizacional formal (Senge, 1990).

Como trabalho e aprendizagem são inseparáveis (BILLETT, 2001), a partir do momento em que as organizações dão condições favoráveis à aprendizagem, trabalhar ao lado de um colega e compartilhar as mesmas tarefas permite aprender fazendo perguntas e recebendo devolutivas dessas atividades. Isso possibilita compreender como o indivíduo percebe a situação, monitora-a e toma decisões (ERAUT, 2011). Essas ações são tácitas e difíceis de serem explicadas, 
principalmente quando envolvem profissionais de diferentes especialidades (ERAUT, 2011).

Em pesquisas empíricas com trabalhadores em ambientes de trabalho, níveis de responsabilidade e especialidades diferentes, Hager (2012) mostrou que todos os indivíduos usam formas de aprender que não lhes foram oferecidas por suas experiências formais de aprendizagem. Aprende-se cometendo erros, praticando habilidades pessoais, aplicando teorias e exercitando habilidades, resolvendo problemas e interagindo com os colegas.

Da mesma forma, Marsick e Yates (2012) revisaram 39 estudos qualitativos sobre AI e concluíram que as experiências de aprendizagem informal estavam integradas ao trabalho e às rotinas diárias, cujo gatilho geralmente era um choque, um desafio ou uma situação de surpresa. A aprendizagem aconteceu nos processos e atividades no local de trabalho, os quais envolviam tentativa e erro, reflexão na ação e sobre a ação, observação de outros, compromisso com o trabalho do outro e solução de problemas com ajuda de terceiros. Para Marsick e Yates (2012), a conversa, as interações sociais, a colaboração, o convívio e as práticas são o coração da $\mathrm{AI}$, assim como o são os relacionamentos positivos e informais com os colegas, os desafios em novas funções (CUNNINGHAM; HILLIER, 2013), fazer perguntas, obter informações, ouvir e observar, refletir, aprender com erros, dar e receber feedbacks (ERAUT, 2011).

Para assegurar os propósitos da AI, os ambientes de trabalho devem sustentar-se como ambientes nítidos e legitimados de aprendizagem (BILLET'T, 2008). O ambiente é fator crítico para a AI no local de trabalho (MARSICK; YATES, 2012). Por isso, para promover um ambiente de aprendizagem no local de trabalho é necessário identificar e depois afrontar os fatores que afetam a aprendizagem no trabalho. Como ferramenta, Eraut $(2004,2011)$ propõe o modelo dos dois triângulos (Figura 1), o qual ilustra o ambiente do trabalho para a aprendizagem e os principais fatores que a influenciam dentro desse contexto.
Figura 1. Fatores que afetam a aprendizagem no trabalho: o modelo dos dois triângulos

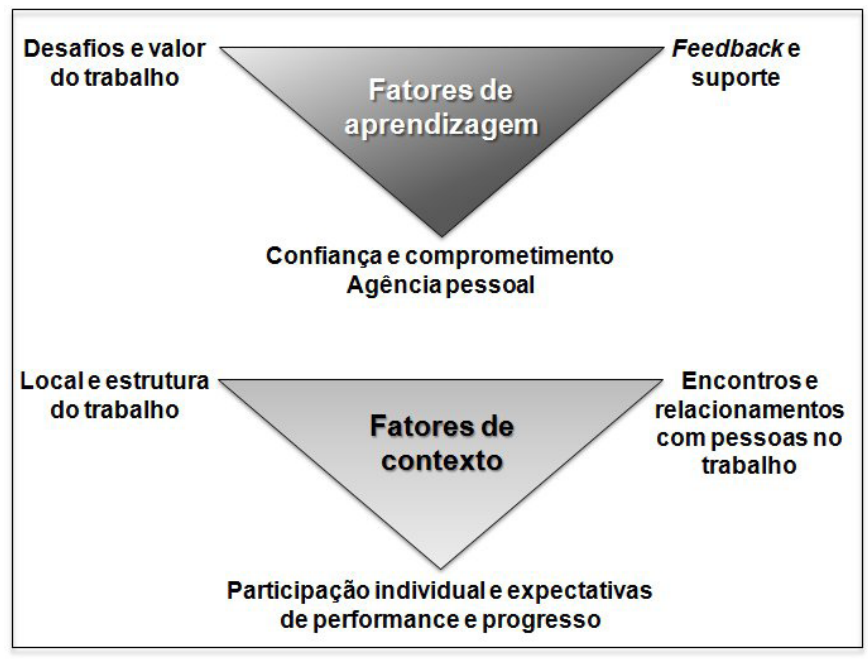

Fonte: traduzido pelos autores a partir de Eraut (2004, p.269).

Nos fatores de aprendizagem (triângulo superior), há uma relação entre desafio, suporte e confiança. Muito daquilo que pode ser aprendido no trabalho depende da confiança para ser pró-ativo e buscar oportunidades de aprendizagem; porém, a confiança surge do quanto cada indivíduo é desafiado no seu cargo ou nas suas tarefas e rotinas diárias, enquanto que a confiança para afrontar tais desafios depende do quanto os indivíduos se sentem apoiados para empreender tal esforço de superação dos desafios (agência pessoal). Se não houver desafio nem apoio suficiente para encorajar a pessoa a buscar respostas para os desafios, então a confiança diminui e, com ela, a motivação para aprender. O feedback é considerado uma forma de suporte à aprendizagem. Também são considerados o comprometimento e o valor dado ao trabalho por clientes e por outros colegas. O triângulo inferior reflete o superior ao focar nos fatores contextuais, ambientais do trabalho. Local, estrutura física do trabalho, receber feedback, papel do gestor e expectativas de melhor desempenho e progresso na organização também afetam a aprendizagem do indivíduo.

A intersecção dos aspectos físicos, culturais e sociais do trabalho numa organização reflete a interação próxima entre elementos físicos e sociais do local de trabalho. Se essa interação é positiva, promoverá e produzirá resultados para estabelecer a base para que a aprendizagem aconteça nos locais de trabalho. Ao contrário, a chance de bons resultados na aprendizagem no local de trabalho será drasticamente diminuída (GERBER, 2006). 
Uma vez explicadas a natureza da AI e a influência dos fatores organizacionais nesta aprendizagem, a próxima seção apresenta a Teoria Pragmática de Bente Elkjaer a fim de elucidar o papel das interações sociais nos processos de AI no local de trabalho.

\section{As contribuições da Teoria Pragmática da Aprendizagem de Bente Elkjaer para a Al}

A Teoria da Aprendizagem Social rejeita as principais suposições da abordagem psicológica da aprendizagem, e suas teses centrais estão alinhadas com a Aprendizagem Informal e com a aprendizagem no local de trabalho (HAGER, 2012).

Para a proposição da sua Teoria Pragmática da Aprendizagem, a autora dinamarquesa Bente Elkjaer (2001, 2004, 2008, 2011, 2013) parte das duas abordagens clássicas de se ver e estudar a Aprendizagem Organizacional (AO). A primeira entende a $\mathrm{AO}$ como uma ferramenta gerencial para desenvolver habilidades tácitas e cognitivas individuais das pessoas na organização. A segunda trata de como a aprendizagem ocorre em ambientes sociais.

A teoria da aprendizagem psicologicamente dominante é aquela que considera a aprendizagem como cognição individual, ou seja, a ideia de que todos os seres humanos nascem numa cultura e devem aprender a adaptar-se a ela e a interiorizá-la (ELKJAER, 2001). A aprendizagem é a transferência e o aumento do conhecimento na mente do indivíduo. A organização é vista como um sistema cujo desenvolvimento dependerá de como e quanto cada indivíduo consegue adquirir de conhecimentos armazenados para guiar suas ações e comportamentos dentro da organização, ou seja, do quanto cada indivíduo pode aprender para beneficiar a empresa (metáfora da aquisição). A principal crítica a essa abordagem concentra-se justamente no fato de que, quando a aprendizagem reside na mente dos indivíduos, o contexto organizacional deixa de ser considerado e investigado como elemento importante para o desenvolvimento da aprendizagem e dos membros organizacionais. Desconsiderando a complexidade dos diversos contextos que os circundam, indivíduo e organização são entendidos e estudados separadamente em suas dimensões epistemológica (voltada à aquisição de conhecimento) e ontológica (voltada à existência e ao desenvolvimento humano), separação que traz à tona questões como: é possível mudar uma organização por meio da aprendizagem individual ou é possível aprender algo sem se relacionar? (BRANDI; ELKJAER, 2011).
Por isso, a segunda abordagem da AO, a Teoria da Aprendizagem Social (TAS), vem como uma resposta às críticas da primeira e descreve a aprendizagem como estando situada nos processos coletivos e na prática social da vida do indivíduo na organização (ELKJAER, 2001). A Teoria da Aprendizagem Social rejeita as principais suposições da abordagem psicológica da aprendizagem, e suas teses centrais estão alinhadas com a Aprendizagem Informal e com a aprendizagem no local de trabalho (HAGER, 2012). O indivíduo aprende porque aprender faz parte da atividade humana e está integrado à vida organizacional cotidiana e ao trabalho e não mais apenas à mente do indivíduo e aos ambientes de educação formal (ELKJAER, 2004). A aprendizagem se dá pela interação do indivíduo com as demais pessoas e não como um processo individual de pensamento que acontece de maneira exclusiva na mente do indivíduo (metáfora da participação). O ponto de partida da aprendizagem são as experiências da vida cotidiana e do entendimento de que aprender é participar dos processos sociais e interagir com eles; e que o indivíduo tanto produz quanto é produto do contexto organizacional.

No entanto, nem todas as respostas à $\mathrm{AO}$ são dadas pela TAS. A limitação dessa perspectiva está na impossibilidade de se unir conceitualmente a dimensão ontológica à epistemológica (ELKJAER, 2004). Em outras palavras, as questões sobre o "como" e o "o que" se pode aprender com a prática ficam sem respostas (ELKJAER, 2004).

Contemplando as duas metáforas, Elkjaer (2004) recorre primeiramente aos conceitos de experiência e investigação de John Dewey. Para o autor, o "como" o indivíduo aprende depende da sua forma de interagir com os seus meios, e a experiência é justamente essa relação cognitiva, que também inclui a emoção, a intuição, a estética e a ética entre sujeitos e mundos. É na experiência que surgem as dificuldades e situações de incerteza as quais levam o indivíduo a resolver problemas por meio da investigação. A investigação, ou o pensamento reflexivo, é um método de experienciar pelo qual é possível ter novas experiências não apenas pela ação, mas também usando ideias e conceitos, hipóteses e teorias como ferramentas para pensar, definindo, assim, "o que" se aprende.

Elkjaer (2004) também busca, na Teoria de Arenas e Mundos Sociais de Anselm Strauss, uma compreensão sobre a relação do indivíduo e os ambientes organizacionais. Esta teoria destaca as tensões, as competições, os conflitos e as trocas, considerando a 
organização como "arenas", nas quais os indivíduos compartilham interesses coletivos (ELKJAER; HUYSMAN, 2008). São esses mundos sociais que definem, consciente ou inconscientemente, o que os seus membros deverão aprender para fazer parte de um mundo ou submundo, seja porque são obrigados (have to), seja porque querem (want to) aprender para poder alimentar seus compromissos, manter a coesão social e a identidade mútua. Os mundos e submundos sociais não são entidades ou instituições sociais fixas. Eles nascem das interações sociais coletivas e assim se constituem (ELKJAER, 2001).

A partir do momento em que há divergências quanto ao compromisso assumido pelos membros dos mundos sociais, surgem as tensões e rupturas, que são responsáveis pelo questionamento da ordem social mantida até o momento e das práticas existentes na organização. Logo, são gatilhos para novas aprendizagens. Num processo cíclico, uma vez renegociados os compromissos e estabelecida uma nova ordem negociada (BRANDI; ELKJAER, 2011), novas tensões e rupturas poderão surgir, abrindo um novo caminho para se aprender (ELKJAER; HUYSMAN, 2008).

Portanto, a abordagem pragmática da $\mathrm{AO}$ (terceira perspectiva) reflete a TAS sem deixar de lado a capacidade humana de investigar e de pensar reflexivamente e ainda explica a ocorrência das novas experiências de aprendizagem no ambiente organizacional (BRANDI; ELKJAER, 2011). A aprendizagem é aqui entendida como a capacidade de se desenvolver e de socializar com o intuito de se tornar membros praticantes e habilidosos que investiguem, pensem reflexivamente, resolvam problemas e compartilhem as soluções e as experiências entre os membros da organização, o que, para Brandi e Elkjaer (2011), é a principal contribuição da teoria pragmática da aprendizagem para a TAS.

\section{Procedimentos Metodológicos}

O estudo qualitativo básico

(MERRIAM, 1998), apoiado numa postura epistemológica interpretacionista e interacionista, é adequado ao alcance do objetivo proposto nesta pesquisa. Coletaram-se informações por meio de entrevistas semiestruturadas em profundidade com 16 servidores técnico-administrativos (14 mulheres e 2 homens) das áreas administrativa e acadêmica de uma faculdade da área de saúde em um câmpus de uma universidade estadual paulista. A escolha de uma instituição de ensino superior se deu pela facilidade de acesso ao campo. Quanto aos sujeitos, como sugere Flick (2009), optou-se por funcionários de diferentes seções e com maior e menor tempo de trabalho na instituição, que fossem capazes de refletir sobre sua experiência e verbalizá-la, garantindo variedade de casos e experiências para que seus discursos ampliassem o alcance dos resultados até que novas ideias ou perspectivas não fossem mais encontradas. Esclarece-se que algumas seções não possuem em seu quadro a função de assistente-administrativo, o que impossibilitou sua escolha para a pesquisa. O tempo dos sujeitos na organização variou de 2-34 anos. Quanto à formação, todos possuem curso superior e a maioria com título de especialista. Neste texto, identificaram-se os sujeitos pela nomenclatura sexoidade ( $\mathrm{M}=$ mulher; $\mathrm{H}=$ homem).

Organizou-se o roteiro da entrevista baseado nos trabalho teóricos e empíricos levantados para esta pesquisa e suas questões versaram principalmente sobre a descrição do trabalho; trajetória de aprendizagem; ambiente de aprendizagem e ambiente organizacional.

Todos os entrevistados foram informados sobre o objetivo do estudo e assinaram o Termo de Consentimento Livre e Esclarecido/TCLE. As entrevistas duraram em média quarenta e cinco minutos, totalizando onze horas e cinquenta e um minutos de gravação. Depois de transcrito, o conteúdo das entrevistas foi exportado para o software WEFTQDA, o qual foi usado somente para gerenciar bases textuais, administrar, procurar, classificar e ordenar trechos de textos das entrevistas, isto é, para separar os elementos ou unidades de sentido propostos pelo processo de categorização de Flores (1994) e não para analisar de qualquer forma os dados obtidos.

Para Flores (1994), a análise dos dados é um processo que consiste na detecção de unidades de significado num texto e no estudo das relações entre elas e em relação ao todo. O processo geral de análise de dados qualitativos proposto por este professor e pesquisador da área da Educação da Universidade de Sevilha, Espanha, é formado pelas atividades de redução dos dados (separação do texto em elementos temáticos; identificação e classificação desses elementos), apresentação dos dados (transformação e apresentação) e formulação de conclusões (geração e verificação de conclusões). Na redução dos dados, 
identificaram-se todas as situações, contextos, atividades, acontecimentos, exemplos e opiniões estruturadas em palavras, orações ou períodos inteiros encontrados nas entrevistas e que tinham relação com os objetivos da pesquisa. Quando se encontrava significação em um determinado elemento, este era codificado e separado em categorias, as quais são um conjunto de elementos de mesma temática. Uma vez identificadas as categorias, definiram-se as metacategorias, que são categorias maiores nas quais se podem agrupar as categorias criadas que têm o mesmo tema ou alguma relação de significado entre elas. Desse processo de análise dos dados, organizou-se um sistema gráfico de categorias (Figura 2) com 3 metacategorias, 16 categorias e 13 subcategorias definidas a posteriori.

Figura 2. Sistema de categorias para o problema de pesquisa proposto

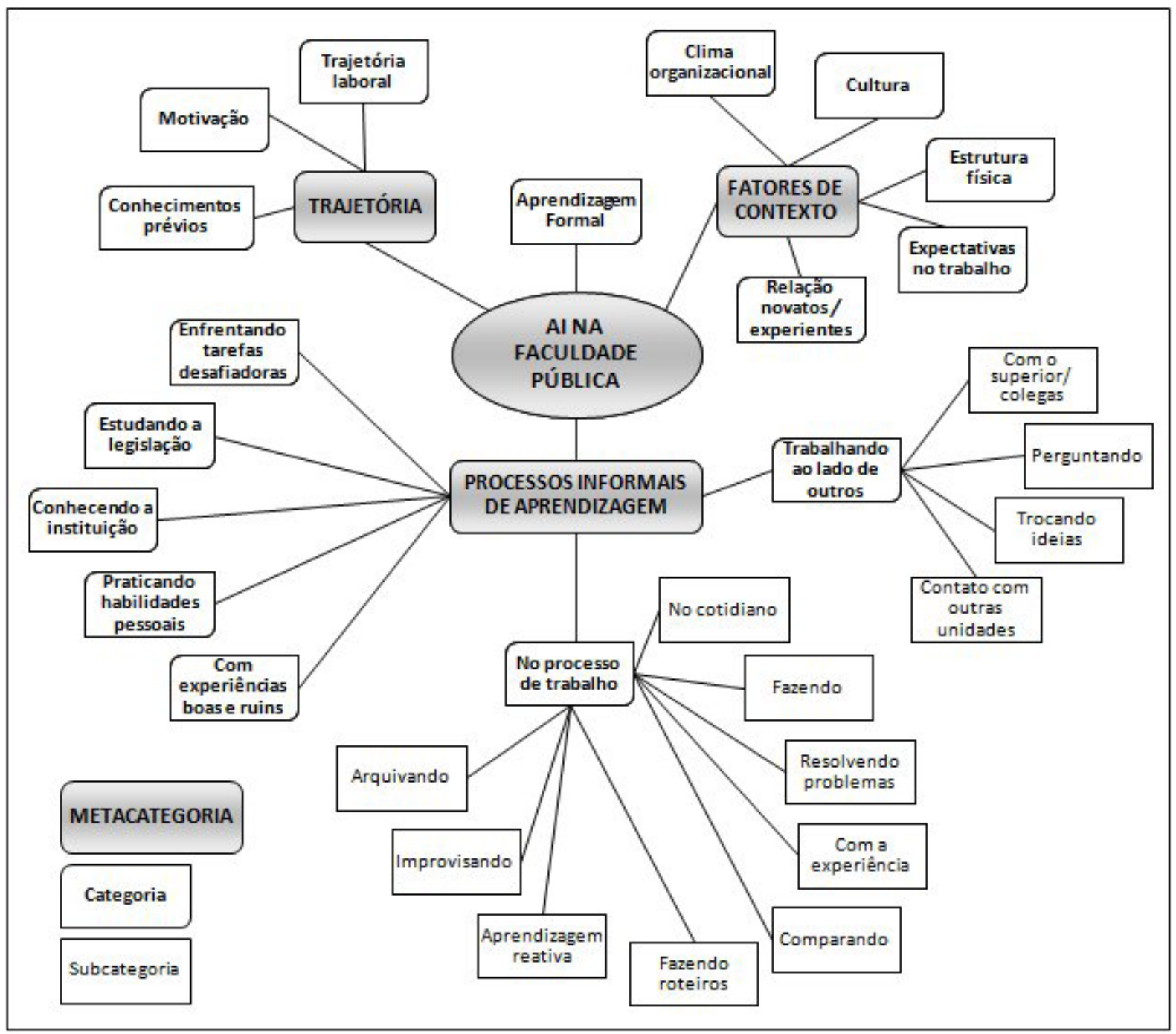

Fonte: elaborado pelos autores a partir de dados primários (2014).

Para dar continuidade à construção dialógica e participação dos sujeitos de pesquisa em outras fases da pesquisa qualitativa, optou-se pelo uso da estratégia de validação comunicativa (KVALE, 1995; ONWUEGBUZIE; LEECH, 2006), a qual consiste em validar o conhecimento afirmado no discurso dos participantes. Solicitouse a 2 sujeitos participantes da pesquisa e a 2 sujeitos não participantes que confirmassem: (a) Em que medida as análises dos pesquisadores representavam a sua própria realidade na Faculdade?; e (b) Em que medida estes textos representavam a realidade da Faculdade?

Foram feitas poucas contribuições no sentido de alterar ou complementar a análise do pesquisador. Os avaliadores expressaram durante todo o tempo da devolutiva o quanto se identificaram com as entrevistas do 
outro; que viram suas opiniões refletidas no discurso dos demais sujeitos de pesquisa; que poderiam ter dito aquilo, porém que foi dito pelo outro; o quanto se sentiram surpresos ao ler o texto e constatar que a sua realidade estava descrita com precisão. Os sujeitos não apontaram nenhuma discordância ou baixa identificação com a realidade analisada pelos pesquisadores.

$\mathrm{Na}$ próxima seção, apresentam-se os resultados decorrentes do trabalho de interpretação do conteúdo categorial das entrevistas realizadas.

\section{Apresentação e análise dos resultados}

\section{Trajetória laboral dos funcionários técnico- administrativos e suas motivações para ingresso no funcionalismo público}

O conhecimento adquirido na carreira pregressa do indivíduo não é considerado após o ingresso do servidor na Faculdade. "A [faculdade] é um universo totalmente diferente" (M-49c) e as atividades são muito especializadas para que seja possível aprender algo antes e aproveitá-lo nas suas atuais funções, mesmo para aqueles que já haviam trabalhado na mesma área de atuação atual. Pelas entrevistas infere-se que, ao entrar na faculdade estudada, o servidor é anulado em suas dimensões epistemológica e ontológica. Não lhe é perguntado quem ele é, o que fez, como chegou até ali e quais são suas expectativas de futuro dentro da nova organização, questões essenciais para se conectar o futuro membro à organização e, consequentemente, a organização ao mundo ao seu redor (ELKJAER, 2001). É como se o indivíduo devesse esquecer-se de sua vida pregressa para poder adaptar-se exclusivamente a novas formas de realidade, de interações e de aprendizagem (ELKJAER, 2013). Dessa forma, a Faculdade assume uma posição realista em oposição a uma nominalista. A posição nominalista afirma que a realidade é construída por meio do conhecimento individual; já a realista presume que não são os membros em sua individualidade, mas o conjunto deles em uma visão do todo que constitui o interesse da organização (HALL, 2004).

As motivações apontadas para se entrar no serviço público foram somente a estabilidade no emprego e a superioridade salarial do setor público em relação à iniciativa privada na região onde está localizada a Faculdade (região noroeste do estado de São Paulo).

\section{A Aprendizagem Informal vivenciada pelos técnicos-administrativos no local de trabalho}

Nesta seção, apresentam-se os processos e as atividades de aprendizagem informal que ocorrem no ambiente de trabalho estudado. A AI é considerada nesta análise como qualquer atividade implícita, intencional, não estruturada (ERAUT, 2004; 2011), advinda da informalidade, da conversação (ELKJAER, 2011), situada no contexto particular do trabalho da Faculdade e influenciada por esse ambiente (GERBER, 2006).

\section{No processo de trabalho}

Os sujeitos evidenciaram que se aprende (a) durante a realização do próprio trabalho, no cotidiano, acompanhando as diversas fases do trabalho, no dia-adia. "A gente aprende mais no dia-a-dia, no cotidiano, fazendo mesmo. Aqui, na hora que der um ciclo de um ano, você aprendeu o serviço da seção" (M-54a). Os entrevistados acreditam que só se aprendem as atividades diárias (b) no cotidiano ao executá-las, ou seja, na prática, repetindo, errando e corrigindo-as. O importante é "pegar o trabalho para fazer" (M-49a e H-51) e refletir sobre como deve ser feito. Da mesma forma, aprende-se (c) resolvendo problemas, "correndo atrás" (M-55) de soluções para novas tarefas, para as intempéries dos sistemas informatizados, falta de informações ou impossibilidade de acesso a elas, e insuficiência de funcionários para atender o volume de trabalho.

Relacionada diretamente à resolução de problemas está a (d) experiência no trabalho. Também chamada de "intuição" e "insight" (M-49c e M-28), com a capacidade de buscar nas experiências de aprendizagem anteriores, aprendem-se respostas para as contingências atuais.

Quando surgem dúvidas de como conduzir determinada atividade na administração da Faculdade, os funcionários recorrem aos processos já encerrados, ou que ainda estão em andamento, para (e) comparar como foi feito anteriormente e, assim, copiar ou adaptar o que pode ser feito no momento presente. Por sua vez, a (f) aprendizagem reativa acontece durante a ação, quando não se tem muito tempo para pensar, porém envolve uma reflexão momentânea sobre o evento (ERAUT, 2004). Acontece quando o servidor questiona se está fazendo corretamente o trabalho e, em caso de erros, em que medida impactará o trabalho de outros na Universidade. 
Os técnicos-administrativos entrevistados ensinam que uma boa maneira de aprender, memorizar e resgatar o "como" tal tarefa deve ser feita é (g) tomar nota de todos os procedimentos e elaborar roteiros, "fazer manualzinho de tudo" (M-46). Os roteiros evitam perguntas excessivas e inoportunas ao colega, dão maior autonomia na condução da tarefa e funcionam como fonte de informação e instruções quando se tem que trabalhar sozinho.

Marcada pelo termo "se vira” (M-49a, M-49b e M-32), a (h) improvisação também aparece nos discursos dos sujeitos e é recorrente na implantação de novas tecnologias; em mudanças na estrutura organizacional, como criação e extinção de unidades organizacionais; implantação de sistemas informatizados; e legislações sem as devidas instruções normativas. Assim, o servidor é obrigado a trabalhar com medidas paliativas até ter recursos necessários para agir de maneira apropriada.

Finalmente, durante a realização do trabalho, aprende-se (i) arquivando, isto é, procedendo a guarda de documentos em processos ou arquivos. A aprendizagem acontece desde que neste trabalho haja consciência sobre a ação ou reflexão sobre a rotina.

A discussão sobre como acontece a aprendizagem das atividades laborais cotidianas pelos técnicosadministrativos no ambiente estudado é alicerçada no pressuposto de que o conhecimento é resultado da participação do indivíduo nas práticas e rotinas organizacionais e de uma complexa rede de relacionamentos (BRANDI; ELKJAER, 2011), porque não há como separar participação no trabalho de aprendizagem (BILLET, 2001). Le Clus (2011) explica que a AI acontece por meio das oportunidades que estão integradas nas rotinas e práticas de trabalho cotidianas. É por isso que os sujeitos entrevistados afirmam que só se aprende o trabalho na prática cotidiana, dada a riqueza de detalhes históricos, legais e técnicos que estão implícitos em qualquer procedimento e rotina a serem executados.

No contexto estudado, a AI não é só uma forma válida de aprendizagem, senão a primeira, a fundamental e a que caracteriza o trabalho dos servidores e lhes permite se socializar no grupo e na organização. Quando afirmam que o trabalho é todo informal e que eles mesmos foram "dando a cara" ao trabalho (M-54a, M-32b), comprovam a constatação de Garrick (1998) de que a AI é importante porque é uma forma válida de aquisição de conhecimento, de as pessoas aprenderem da experiência (com o tempo, com o terminar dos ciclos de trabalho nas seções), sustentada na concepção de aprendizagem como processo (e não só como resultado de cursos e treinamentos), por meio da qual as pessoas, sozinhas ou com colegas de trabalho, encontram-se pessoalmente (no dia-a-dia) para refletir, validar, transformar, dar significado e integrar seus diferentes tipos de conhecimento.

\section{Trabalhando ao lado de outros}

Esta categoria representa atividades de aprendizagem que acontecem durante a realização do próprio trabalho na presença e na interação com o outro, caracterizando a natureza social da aprendizagem no contexto estudado.

Quando questionados sobre com quem aprendem seu trabalho, os respondentes indicaram o nome de um (a) colega ou do próprio superior. É na interação e na relação dialógica cotidiana entre os funcionários no local de trabalho que se desenvolvem as atividades de aprendizagem apresentadas, alicerçadas na atividade básica de perguntar ao superior/colega.

M-32a resume que (b) perguntar é a única forma de aprender no seu local de trabalho. A aprendizagem depende da qualidade das interações no local de trabalho (ERAUT, 2004). Embora se sintam à vontade para perguntar, os servidores indicaram displicência nesse processo por parte dos colegas e superiores, e relataram situações de falta de paciência, centralização do trabalho, sensação de estar perturbando o outro com perguntas excessivas, por não parar o trabalho e olhar a pessoa nos olhos enquanto se ensina. Esses comportamentos podem limitar as discussões relacionadas ao trabalho, o suporte à aprendizagem, as devolutivas sobre o desempenho e as sugestões de melhoria. Eraut (2011) chama a atenção para a qualidade das interações sociais, a qual está diretamente relacionada com o que e como se aprende.

Além de perguntar, aprende-se (c) trocando ideias. Os servidores acreditam que cabe ao líder ter iniciativa e incentivar a prática no grupo, porém cabe a todos compartilhar ideias. A troca de ideias acontece quando se descobre uma novidade, quando se dá e recebe uma informação, na busca de soluções, no compartilhamento de conhecimentos e de boas práticas nas rotinas de trabalho. Dada a natureza multicâmpus da universidade, é comum o (d) contato e o compartilhar conhecimento entre funcionários da faculdade com diferentes campi por telefone, 
e-mail, listas de discussão e videoconferência (H51). O contato é fomentado pelos novos sistemas informatizados e pela operacionalização das legislações. Ao comparar a experiência do outro com a sua própria realidade na Faculdade, os funcionários buscam aprender as melhores práticas nas rotinas de trabalho para minimizar incertezas e erros, acentuar a segurança na ação, demonstrar comportamento proativo na busca de conhecimento novo e fortalecer e ampliar a sua rede de contatos.

Escutar, conversar, trocar ideias, resolver problemas, ensinar o colega, colaborar com ele e assumir desafios são relatados como o coração da AI e como fontes-chave para os trabalhadores aprenderem suas atividades no trabalho (BILLET, 2001; GERBER, 2006; ERAUT, 2011; HAGER, 2012; MARSICK; YATES, 2012; CUNNINGHAM; HILLIER, 2013; LE CLUS, 2013). Os sujeitos acreditam que se aprende muito mais "passando pro outro aquilo que aprendeu, com troca de experiência" (M-49a); com demonstrações nítidas de coleguismo, de camaradagem, de solidariedade diante da necessidade do outro (M-54). Gerber (2006) afirma que, ao ensinar o outro, o indivíduo aprende e se sente bem em relação aos demais e a si mesmo. Os indivíduos ganham experiência pelo resultado de como eles interagem com as pessoas (ELKJAER, 2004). Logo, pensar em espaços no local de trabalho que permitam um relacionamento positivo entre os membros da organização é fundamental para empreender a AI e garantir que os funcionários se sintam seguros nas suas tomadas de decisão e, principalmente, que possam voltar atrás (CUNNINGHAM; HILLIER, 2013).

\section{Enfrentando tarefas desafiadoras}

Os desafios na própria função ou em outra são um gatilho para a AI no local de trabalho. A aprendizagem aconteceu por meio de solução de problemas, frequentemente com ajuda de terceiros em conversas, interações sociais, colaboração, relacionamentos e práticas, o que, segundo Marsick e Yates (2012), são a essência da AI. A conversa com aqueles que já ocuparam o cargo temporariamente, com aqueles que ocupam cargo semelhante, a colaboração na troca de modelos de documentos diversos e de instruções são as formas mais mencionadas pelos sujeitos que enfrentam o desafio da substituição temporária de cargos.

Para resolver os desafios cotidianos no trabalho, os técnicos-administrativos afirmaram buscar respostas nas suas experiências em empregos anteriores e em contato com outros membros da organização atual. Ao considerar que não é possível aprender algo sem se relacionar (BRANDI; ELKJAER, 2011), a forma como o indivíduo interage com seus meios definirá como ele aprenderá. Ao adotar uma estratégia de resolução do problema, o indivíduo reflete sobre a ação escolhida e verifica o que aprendeu, tanto com os resultados desejados quanto com os indesejados (MARSICK; WATKINS, 2001). Em ambos os casos, o líder ou o grupo devem dar suporte necessário e devolutiva positiva para aumento da motivação e da confiança do indivíduo (ERAUT, 2004).

\section{Estudando a legislação}

A regulação do trabalho por legislações específicas e a alta formalização dos procedimentos organizacionais dão caráter técnico, perito, aos técnicos-administrativos. Por isso, os servidores afirmam que seu trabalho é complexo e que se aprende por meio de consulta e estudos da legislação da Universidade.

A legislação auxilia na resolução de problemas quando não há precedentes para basear uma solução. Ademais, os servidores afirmam que, quando as orientações fornecidas por eles se baseiam em justificativas técnicas extraídas da legislação, se ganha credibilidade, passase segurança, pois não há subjetividade no julgamento da situação. Acreditam, ainda, que o conhecimento sério e profundo das legislações que regem o trabalho na Faculdade desenvolve o senso crítico para saber, inclusive, diferenciar o que se trata de uma questão cultural ou empírica daquilo que é legal, e onde está o seu embasamento teórico.

As burocracias estatais são um exemplo claro da persistência e da resiliência de organizações que mantêm até hoje os princípios coercitivos das teorias clássicas da organização. Embora façam apologia a quebras de paradigmas, qualquer usuário de seus serviços públicos, seja ele interno ou externo, pode comprovar o quanto a organização possui um ambiente complexo, estrutural e psicologicamente (CUNHA, 2011). Dessa forma, os funcionários técnico-adminsitrativos se valem da formalização organizacional para se tornarem especialistas em suas tarefas, impondo procedimentos altamente formalizados, forçando seus membros a concordarem com suas orientações. A administração conduzida por esse tipo de funcionário é baseada na disciplina, e os indivíduos obedecem às orientações porque percebem que a ordem mantida e baseada em regras é a melhor forma de se atingir os objetivos (ADLER; BORYS, 
1996). Essa função coercitiva da burocracia é vista como negativa quando o indivíduo na organização assume que ela é essencialmente coercitiva e isso permite anular sua autonomia. Outra consideração negativa a ser feita são as assimetrias de poder geradas $\mathrm{e}$ as divergências nos interesses econômicos. Sobre essa última, quando claramente se percebe que a organização caminha contra seus próprios interesses limitada pela sua própria formalização (ADLER; BORYS, 1996).

No entanto, nem tudoé ruim na burocracia profissional. O trabalho baseado em legislações ajuda na redução de conflitos de papéis e da ambiguidade (HALL, 2004). Ainda, quando o funcionário consegue perceber ao menos uma coincidência entre seus próprios objetivos com os da universidade, ele pode abrir as portas para uma formalização que contribua com a eficiência da organização, propondo e implementando rotinas que facilitem seu trabalho altamente formalizado e que ao mesmo tempo aumente o desempenho de suas tarefas, o da organização e seu orgulho em ser membro daquela instituição (ADLER; BORYS, 1996). O que não é tarefa fácil, uma vez que a própria legislação criada, e sob a qual terão seu desempenho avaliado, impede-os de buscar uma maior autonomia. Conforme observado em muitas pesquisas nessa área, essa rigidez também pode conduzir a um grande sentimento de insatisfação, impotência, alienação e isolamento psicossocial no trabalho (HALL, 2004).

\section{Conhecendo a instituição}

Conhecer a instituição auxilia na aprendizagem e na compreensão do trabalho e está relacionado a três fatores principais citados pelos sujeitos de pesquisa. O primeiro é ter parentes que tenham trabalhado na faculdade e que de alguma forma tornaram a realidade da Faculdade acessível, familiar e sem mistérios, pois a ambientação acontece muito mais rápido do que quando não se possuem esses vínculos. O segundo é ter trabalhado em alguma unidade organizacional (seção ou departamento) cuja natureza do trabalho lhe permita ter uma visão sistêmica do trabalho da universidade. $\mathrm{O}$ terceiro aspecto diz respeito à participação do servidor em órgãos colegiados locais (do câmpus investigado), e centrais (da Reitoria) (H-51).

A participação efetiva de um membro nessas instâncias decisórias pode ajudar na implementação de uma decisão (HALL, 2004). Assim, as participações em comissões, comitês, projetos e outras responsabilidades que vão além da descrição do cargo do indivíduo, geralmente, pode fazê-lo se sentir mais satisfeitos com o seu desenvolvimento na carreira, por ter a oportunidade de contribuir com a organização e por poder se preparar para assumir responsabilidades maiores (CUNNINGHAM; HILLIER, 2013).

\section{Praticando habilidades pessoais}

Os indivíduos demonstram, consciente ou inconscientemente, as características pessoais de seu comportamento nas suas experiências de aprendizagem no local de trabalho (GERBER, 2006). Assim, os servidores entrevistados acreditam que certas habilidades - como ter proatividade, iniciativa, flexibilidade, facilidade em aprender, interesse, intolerância ao erro, praticidade, responsabilidade, curiosidade - são facilitadores que instigam sua aprendizagem na faculdade. Por outro lado, ser ansioso ou tímido constitui-se em barreira para a aprendizagem. As entrevistas revelaram que os técnicos-administrativos fazem questão de destacar seu comportamento proativo para atenuar o estigma do funcionário público de trabalhador acomodado, até porque muitos também já trabalharam na iniciativa privada, onde o comportamento proativo tende a ser mais necessário para a própria manutenção do emprego do indivíduo.

O comportamento proativo é importante porque está relacionado com muitos processos e resultados pessoais e organizacionais e porque é um importante facilitador nos processos e resultados da aprendizagem (PARKER; SPRIGG, 1999; CRANT, 2000). É uma tendência geral a pessoa proativa buscar a aprendizagem (SONNENTAG, 2003). É um ideal de vida, é uma busca pessoal, simplesmente porque a pessoa é assim (M-49b).

\section{Com experiências boas e ruins}

As experiências boas ou ruins vividas pelos membros de uma organização no local de trabalho podem trazer-lhes aprendizado, pois conflitos e tensões são gatilhos para a aprendizagem (ELKJAER, 2001). Para os funcionários entrevistados, as experiências ruins concentram-se em duas origens principais de tensões e conflitos: aquelas relacionadas com a natureza do trabalho (como adaptação do indivíduo a novas tecnologias, volume excessivo de trabalho, centralização de tarefas e falta de funcionários) e aquelas que surgem na interação cotidiana com colegas e superiores (como diferenças de opinião e mentalidade, informalidade no tratamento, etiqueta 
organizacional e invasão de privacidade). Por sua vez, as boas emoções mais mencionadas foram gratidão, comprometimento, prazer e amor, no trabalho e pelo trabalho.

Diante dos achados nas entrevistas, nota-se que as emoções são produtos da prática social dos servidores no local de trabalho da Faculdade e que são uma interferência indesejada no processo de aprendizagem. Vince e Saleem (2004) explicam que tanto para gestores quanto para os demais funcionários de uma organização há dificuldades em se entender quando e onde as emoções são úteis como defesa social, o que pode ou não pode ser expresso no local de trabalho, se e como o uso estratégico das emoções realmente leva a algum fim desejado. Essas dificuldades também estão presentes no ambiente estudado.

Notou-se pelas entrevistas que as emoções, principalmente as boas, estão imbricadas (no sentido de embedded) na motivação do servidor, sendo isto o que tem ajudado a mantê-los na Faculdade. Contudo, acredita-se que os servidores sejam maduros suficientemente para perceber que emoções boas e ruins coexistem (M-32a e M-44b) e que podem gerar boas e más aprendizagens (SIMPSON; MARSHALL, 2010), porque a aprendizagem acontece no curso de toda sorte de situações, como nas histórias contadas pelos sujeitos entrevistados, gerando resultados bons e ruins e não somente resultados positivos como defende a teoria organizacional dominante. Como sugere Fineman (BENOZZO; COLLEY, 2012), o termo ideal para tratar as emoções deveria ser "cogmotion" (cognition + emotion), pois devem ser vistas como parte de um único processo social, intrincadamente interligado e interdependente.

\section{Os fatores organizacionais do ambiente estudado e sua influência nas interações sociais e no contexto da aprendizagem}

Esta seção trata dos aspectos levantados pelos técnicos-administrativos sobre clima e cultura organizacionais, estrutura física, expectativas no trabalho e relações entre novatos e experientes, entendidos aqui como fatores que podem favorecer ou dificultar as interações sociais e, por consequência, a aprendizagem no ambiente estudado.

\section{Cultura, clima organizacional e estrutura física}

Embora tenham considerado como prazeroso e saudável, os técnicos-administrativos acreditam que o clima organizacional no câmpus depende das pessoas, de como elas mapeiam o ambiente e dão significado às coisas e situações subjacentes às suas rotinas diárias. "Não existe lugar nem melhor nem pior para se trabalhar. Vai depender da pessoa" (M-28).

Moran e Volkwein (1992) mostraram que muito daquilo que é denominado como prática ou procedimento cotidiano numa organização pode ser rotulado como uma convenção, um costume, um hábito, ou uma tradição que está no centro da cultura da organização; e que é por meio dessas práticas diárias compartilhadas que a cultura afeta os membros e constitui o clima organizacional. Assim, a forma pela qual os indivíduos aprendem e compartilham essas práticas ajuda a validar a cultura da organização e a estabelecer o clima organizacional.

Apesar da forte carga política e de poder para indicação de cargos de liderança, a mudança no papel do líder, de uma postura autoritária para uma visão democrática, vem acontecendo nos últimos 30 anos e ajuda na propagação de novos conceitos, percepções e culturas, o que pode ajudar a inibir a cultura do "sempre foi assim" e do "é cultural", abrindo espaço para novas aprendizagens no trabalho desses servidores. No entanto, Mahler (1997) adverte que os funcionários novatos podem não refletir sobre as práticas porque os experientes usam essa cultura como desculpa para defender rotinas já constituídas ou como origem de resistência à mudança.

A dispersão das atividades do câmpus em duas unidades com diferentes localizações geográficas, a falta de clareza na comunicação da diretoria com as unidades organizacionais e a superioridade no tratamento de docentes em relação ao técnico-administrativo também foram destacados pelos entrevistados como aspectos influenciadores do clima e da aprendizagem organizacionais.

O clima são ações e reações dos membros da organização (PUENTE-PALACIOS, 2002) quando seus grupos interpretam, constroem e negociam a realidade por meio da criação de uma cultura organizacional (MORAN; VOLKWEIN, 1992). Se o funcionário não se percebe satisfeito no ambiente construído, ele não aprende (M-32b). O aprender dependerá diretamente de como o servidor percebe e o valor que dá a cada fator motivacional ou higiênico, entre eles, principalmente, a comunicação com a diretoria e o arranjo físico das instalações da Faculdade. 


\section{Expectativas no trabalho}

Alcançar novas posições hierárquicas dentro da faculdade é ao mesmo tempo político e meritório. $O$ quanto a organização se constitui num espaço de crescimento para o indivíduo definirá aquilo que poderá e deverá ser aprendido. M-55 aconselha que embora a indicação seja política, cabe ao indivíduo capacitar-se da melhor forma possível para que, quando a oportunidade surgir, esteja preparado para assumi-la. "Tem que ganhar a confiança" (M-55). Ainda indica que a competência saber ser-agir é a que deverá ser dominada pelos funcionários atuais para fazer frente às novas demandas e cenários incertos da organização.

\section{Relação novatos versus experientes}

Pelas entrevistas, infere-se que, sem o auxílio, sem as diversas interações e sem o acompanhamento dos mais experientes, o trabalho na faculdade se torna um labirinto difícil de percorrer, pois as referências documentais são de difícil compreensão dado o currículo situado da aprendizagem na faculdade e a escassez de treinamentos formais.

$\mathrm{Na}$ visão de novatos e experientes, a diferença de idade, ou de geração, não parece ser uma barreira ou um agente dificultador na autossocialização do novato. Essa percepção de diferença está no "o que" e no "como" novatos ou experientes aprendem e no uso que fazem dessa aprendizagem e não em suas idades. Os novatos não têm medo de escolher com quem querem interagir, o que querem aprender e como vão aplicar esse conhecimento no cotidiano. É o comportamento proativo de cada um que definirá qual aprendizagem tem papel importante para diminuir as incertezas e aumentar os conhecimentos relevantes (ASHFORTH; SLUSS; SAKS, 2007) para afrontar o dia a dia.

Das entrevistas surgiu o submundo dos "aposentandos", constituído por funcionários experientes que estão na iminência de aposentadoria, possui um comportamento laboral característico, o qual pode ser explicado por meio do primeiro triângulo do modelo de Eraut (2004) sobre os fatores que influenciam a aprendizagem no trabalho. Esses servidores experientes tiveram muitos desafios no início de suas carreiras, assim como os novatos estão tendo no momento de suas contratações. A confiança e o comprometimento inicial são altos para poder vencer esses desafios impostos pelo ambiente estudado. No entanto, com o passar do tempo na organização, a falta de suporte e de feedback adequado para a aprendizagem favorecem a diminuição da agência pessoal e, por consequência, o valor dado ao trabalho e à Faculdade. Os novatos percebem essa realidade e alertam para que os experientes se conscientizem do impacto que eles têm sobre os novatos e não os contaminem com esse comportamento (M-28).

\section{Aprendizagem formal}

Aprende-se formalmente por meio de cursos e treinamentos oferecidos pela Universidade e organizados pelos próprios funcionários. Os entrevistados dão importância à educação formal e reconhecem os esforços da Universidade nesse sentido, no entanto, assim como Eraut (2011), apontam que os treinamentos são importante cenário de encontro com colegas para troca de experiências sobre o tema do treinamento, ou para a busca de soluções dos problemas da realidade, ou ainda no estabelecimento de redes de contatos, às quais possam recorrer quando retornam dos treinamentos e enfrentam os desafios das atividades cotidianas, especialmente na operação de sistemas informatizados.

Os cursos e treinamentos promovidos pela Universidade e pela Faculdade possuem características da aprendizagem formal (GERBER, 2006): a) a aprendizagem é descontextualizada e os conceitos ensinados são gerais e aplicáveis a qualquer ambiente; b) a aquisição de conhecimento é priorizada no sentido de que a aprendizagem acontece na dinâmica individual de adquirir conhecimento e aplicá-lo. O conhecimento é maior à medida que mais teoria se armazena e se aplica; c) o foco está em quem ensina, porque se priorizam o desempenho do instrutor, o conteúdo e a estrutura do que é ensinado. No entanto, os funcionários tentam caracterizar esses treinamentos atribuindo-lhes características informais: eles discutem entrem si e buscam adequar o tema e o conteúdo visto durante o evento considerando as especificidades do ambiente no qual trabalham; aplicam, testam e dão devolutiva para a sua rede de contato sobre o conteúdo visto abordado no treinamento, garantindo, dessa forma, o desenvolvimento contínuo da aprendizagem. Também, durante os treinamentos, os funcionários tentam mudar o foco do "quem ensina" para o "quem aprende" ao trazer para a discussão problemas pontuais da sua unidade universitária e não da coletividade. Face a isso, pode-se afirmar que há mais elementos de informalidade do que de formalidade nos treinamentos (MALCOLM; HODKINSON; COLLEY, 2003). 


\section{Considerações Finais}

A aprendizagem no local de trabalho foi entendida sob a luz da Teoria Pragmática da Aprendizagem de Bente Elkjaer $(2004,2011)$ como uma construção social, situada nos processos coletivos e na prática cotidiana da vida do indivíduo na organização.

Identificou-se que os funcionários da faculdade aprendem suas tarefas informalmente, por meio da prática no local de trabalho, resolvendo problemas, comparando, refletindo na ação, fazendo roteiros, improvisando, arquivando, perguntando e trocando ideias com o superior e colegas da própria ou de outra unidade da instituição, com quem constroem uma rede de relacionamentos contributiva. Enfrentar tarefas novas e desafiadoras em outros cargos ou funções também é um gatilho para a aprendizagem desses funcionários, bem como conhecer o funcionamento da estrutura organizacional e estudar a legislação interna e externa pertinentes à sua função e organização. Essas ações são incentivadas pelo comportamento proativo do funcionário, o qual carrega consigo e o aplica no local de trabalho. As interações também despertam emoções como gratidão, comprometimento, prazer e amor no trabalho e pelo trabalho, as quais ora apoiam ora suprimem a aprendizagem.

Todas essas evidências corroboram os conceitos norteadores da AI usados neste trabalho, os quais enxergam a AI como sustentada na concepção de aprendizagem como processo e não como resultado de uma atividade formal (GARRICK, 1998; HAGER, 2012), controlada pelos funcionários em termos de amplidão, profundidade e tempo (MARSICK; YATES, 2012), induzida por um processo de reflexão crítica, pela ação, pela proatividade e incrustada no contexto organizacional e nas práticas cotidianas sociais, tanto dentro de uma organização quanto para a vida (MARSICK; WATKINS, 2001; GERBER, 2006; LE CLUS, 2011). Principalmente no ambiente estudado, a AI é motivada, direcionada e sustentada pelos próprios interesses e intenções do indivíduo (MARSICK; WATKINS, 2001; GERBER, 2006). Também, dentro da proposta da estrutura conceitual de aprendizagem no local de trabalho de Jacobs e Park (2013), as experiências de aprendizagem identificadas não são estruturadas. Para se compreender que a aprendizagem no contexto organizacional estudado emerge informalmente como parte da existência humana e do desenvolvimento no cenário social do trabalho, organizouse um modelo explicativo (Figura 3), o qual representa a dinâmica dessa aprendizagem e evidencia o papel das interações que acontecem entre os mundos e submundos identificados no ambiente estudado a partir da Teoria Pragmática da Aprendizagem de Bente Elkjaer (2004, 2011). 
Figura 3 . Processo de Aprendizagem Informal no contexto da faculdade estudada

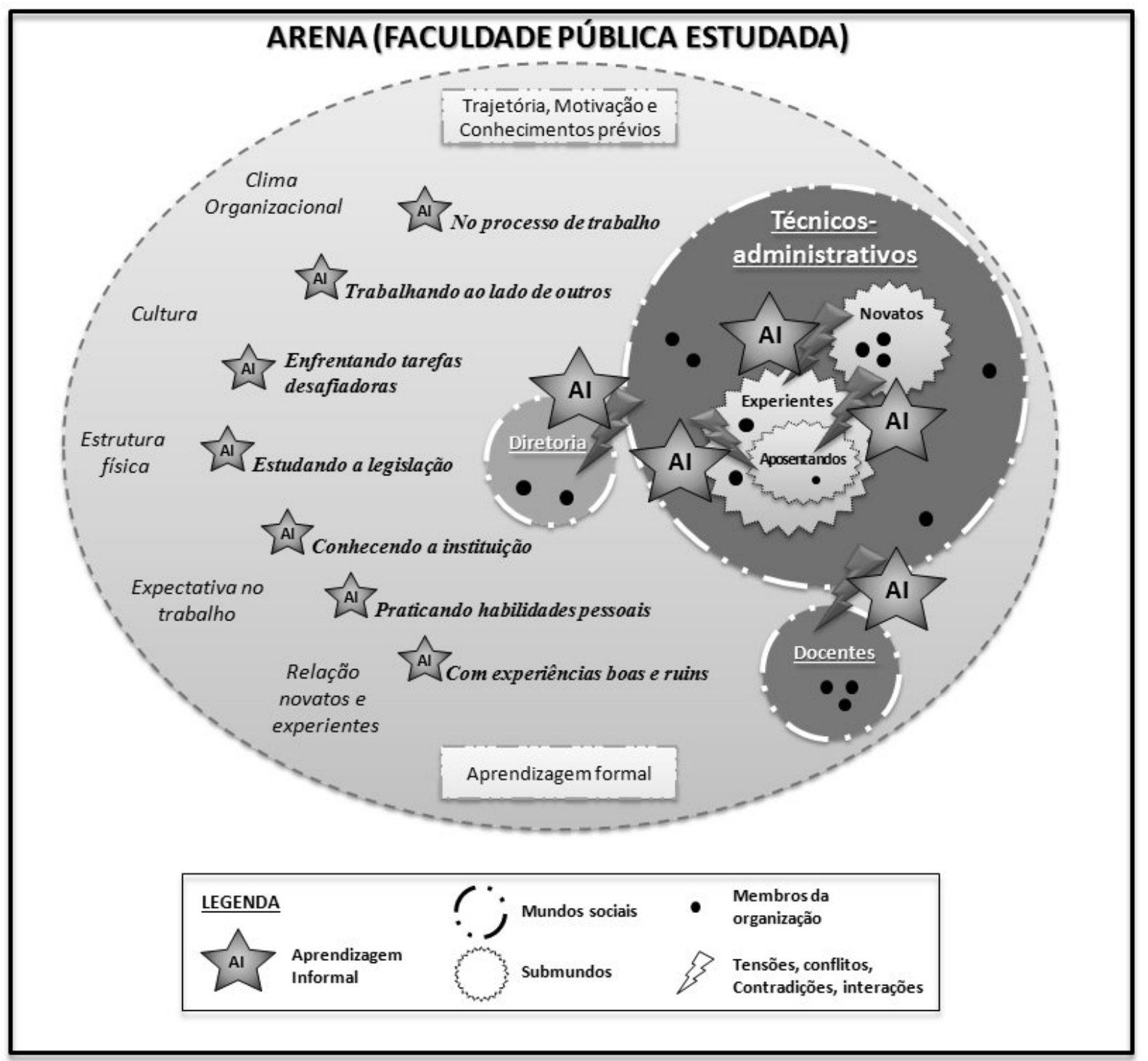

Fonte: elaborado pelos autores a partir de dados primários (2014).

A faculdade estudada é a arena dos mundos sociais vivenciados por servidores técnico-administrativos e docentes, além da diretoria. Do mundo dos técnicos-administrativos emergem os submundos novatos, experientes e "aposentandos". Esses mundos e submundos são produzidos pelas diferentes maneiras de entender as ações, atividades e valores organizacionais (ELKJAER; HUYSMAN, 2008). As linhas pontilhadas denotam que não há um limite definido entre cada mundo social e que todos eles estão abertos às interferências de outras arenas, mundos, submundos e contextos ambientais internos e externos. Os docentes e a diretoria mantêm distanciamento na compreensão do que é o trabalho dos técnicos-administrativos, da legislação que o rege e controla e da característica pública das tarefas cotidianas. A necessidade de atender a esses compromissos organizacionais em detrimento dos interesses pessoais dos membros dos grupos citados é fonte de contradições, tensões e conflitos, logo um gatilho para a aprendizagem. A natureza pública da organização exige que os funcionários aprendam a desenvolver parcerias entre si com o objetivo de alcançar resultados que sejam valorizados pela sociedade civil (RASHMAN et al., 2009). De dentro do mundo dos técnicos-administrativos, emergem os submundos dos novatos e dos experientes. Do submundo dos experientes ainda irrompe o submundo dos "aposentandos". A intensa entrada de novatos, com a consequente forte renovação do quadro funcional da faculdade, permite que uma nova voz questione as ações, atividades e valores da organização, o que faz eclodir situações de contradição, tensões e conflitos. Em alguns momentos, os novatos introduzem novas perspectivas 
de pensamento sobre as atividades de trabalho, seja por influência do seu histórico laboral, do domínio de novas tecnologias ou, talvez, da sua condição sóciocultural, divergindo do posicionamento conservador dos experientes. Os experientes se consideram mais compromissados com a organização do que os novatos, porém, tanto os novatos que possam ser considerados mais compromissados com sua carreira quanto aqueles que acatam a cultura organizacional do grupo e da organização aprendem suas tarefas cotidianas no local do trabalho com os próprios colegas e com o superior, pois a AI é a maneira imperante de se aprender nesta unidade universitária. A aprendizagem formal institucionalizada só acontece por necessidade de atendimento a legislações e diante da implantação de novas tecnologias.

Quando surge a dúvida no julgamento de alguns técnicos-administrativos, se a presença ou ausência de proatividade no comportamento dos novatos é devido à questão de choque de gerações, revelase o submundo dos "aposentandos", formado por membros que da mesma forma são experientes, entretanto estão na iminência da aposentadoria e, por esse motivo, replicam os comportamentos de interesses particulares e com os de suas carreiras presentes em alguns novatos. É dessa tensão no nível de compromisso dos membros com os valores, ações e atividades organizacionais que a aprendizagem de novo se depreende (ELKJAER, 2004; 2011; ELKJAER; HUYSMAN, 2008): os novatos precisam aprender as atitudes, os comportamentos e os conhecimentos necessários para poderem participar como membro legítimo da faculdade, enquanto que os experientes continuam renovando seus conhecimentos por meio das incertezas inseridas pelo próprio ambiente organizacional e pelos novatos. Elkjaer e Huysman (2008) esclarecem que é mais importante estar atento aos compromissos de cada mundo e submundo sociais e às tensões que eles produzem do que entender a aprendizagem como um processo harmonioso de inclusão, união, ação e mesmo repertório de práticas compartilhadas, porque com o olhar fixo nesses compromissos e tensões é que se podem ver possibilidades de negociações produtivas e renegociações de ação e valores. A ênfase do ambiente organizacional deve estar na aprendizagem, produzindo mudanças no local de trabalho e que essas novas direções sejam aceitas pelos membros e que eles possam, assim, ter condições de lidar com novas pressões em seus trabalhos (GERBER, 2006).
Gerber (2006) também afirma que a cultura de um grupo de trabalho (de um mundo ou submundo social), isto é, a maneira que eles se comportam no local de trabalho, precisa refletir uma capacidade dinâmica de aprendizagem. No entanto, em muitas organizações, assim como na faculdade estudada, o envolvimento do quadro funcional e dos líderes na cultura da organização tende a ser muito mais estático do que dinâmico. $O$ fato de a característica do trabalho ser pública e de intensa regulação legal fertiliza o terreno para que a "cultura do silêncio" cresça e se propague. $\mathrm{O}$ funcionário não reflete e aceita a forma de se trabalhar historicamente definida, o que limita a proposição de mudanças radicais nos procedimentos e rotinas de trabalho que possam efetivamente contribuir com uma mudança cultural e construção de um ambiente mais solidário e espontâneo, pois é da naturalidade nas interações que a AI desperta (GERBER, 2006).

Por sua vez, os líderes têm papel fundamental em unir os funcionários para criar um ambiente que conduza à aprendizagem (RASHMAN et al., 2009), estimulando nos funcionários a capacidade de aprendizagem e de resolução de problemas. Para isso, quem lidera deve desenvolver a capacidade de comunicação e usá-la com efetividade, pois a comunicação é um componente central que afeta a aprendizagem (MORAN; VOLKWEIN, 1992; MAHLER, 1997). Contudo, o discurso recorrente na pesquisa mostrou que não há preocupação na preparação para as funções de chefia, pois são todos cargos de confiança.

Os servidores que estão subordinados a líderes criadores de contextos organizacionais favoráveis ao crescimento e à aprendizagem relatam que eles os auxiliam na aprendizagem, que seu chefe consegue examinar o ambiente social do trabalho e identificar múltiplas formas de ensinar o que cada funcionário tem de aprender. Em contrapartida, ainda há uma maioria de técnicos-administrativos sob o controle e a direção de seus chefes, os quais não compreendem que a aprendizagem do trabalho depende do ambiente social no qual seus subordinados estão inseridos e, por esse motivo, não disponibilizam tempo nem espaço para que os indivíduos reflitam sobre suas práticas; não criam e tampouco fomentam oportunidades para se trabalhar e resolver problemas em grupo; não alimentam uma atmosfera em que se possa aprender com os erros; não permitem que se busquem soluções para problemas identificados nas atividades normais do trabalho; não encorajam a participação nas definições de políticas e decisões que afetem os 
processos de trabalho, como participação nos diversos órgãos colegiados da faculdade e da universidade.

Ao adaptarmos o modelo dos dois triângulos de Eraut (2004) para explicar a influência do contexto organizacional da Faculdade estudada na aprendizagem (Figura 4), infere-se das entrevistas que as práticas organizacionais no ambiente estudado são orientadas a processos, funções e normativas, todos de alto controle, o que caracteriza a natureza do trabalho e interfere nas formas de aprendizagem. O fato de a socialização dos novatos ser automotivada e não institucionalizada ajuda a desenvolver no indivíduo um comportamento proativo inicial para a aprendizagem (Figura 4 - triângulo superior). Contudo, não se notam apoio, suporte e feedback necessários durante os processos de aprendizagem identificados. Assim, os técnicos-administrativos possuem desafios, porém sem apoio não geram a confiança para continuarem a ser proativos, o que pode levar, a longo prazo, à desmotivação e à perda de valor dado ao trabalho, pois muito da superação dos desafios (agência pessoal) cabe somente às iniciativas isoladas desses funcionários.

Figura 4 . Fatores de aprendizagem e de contexto que afetam a aprendizagem na faculdade estudada

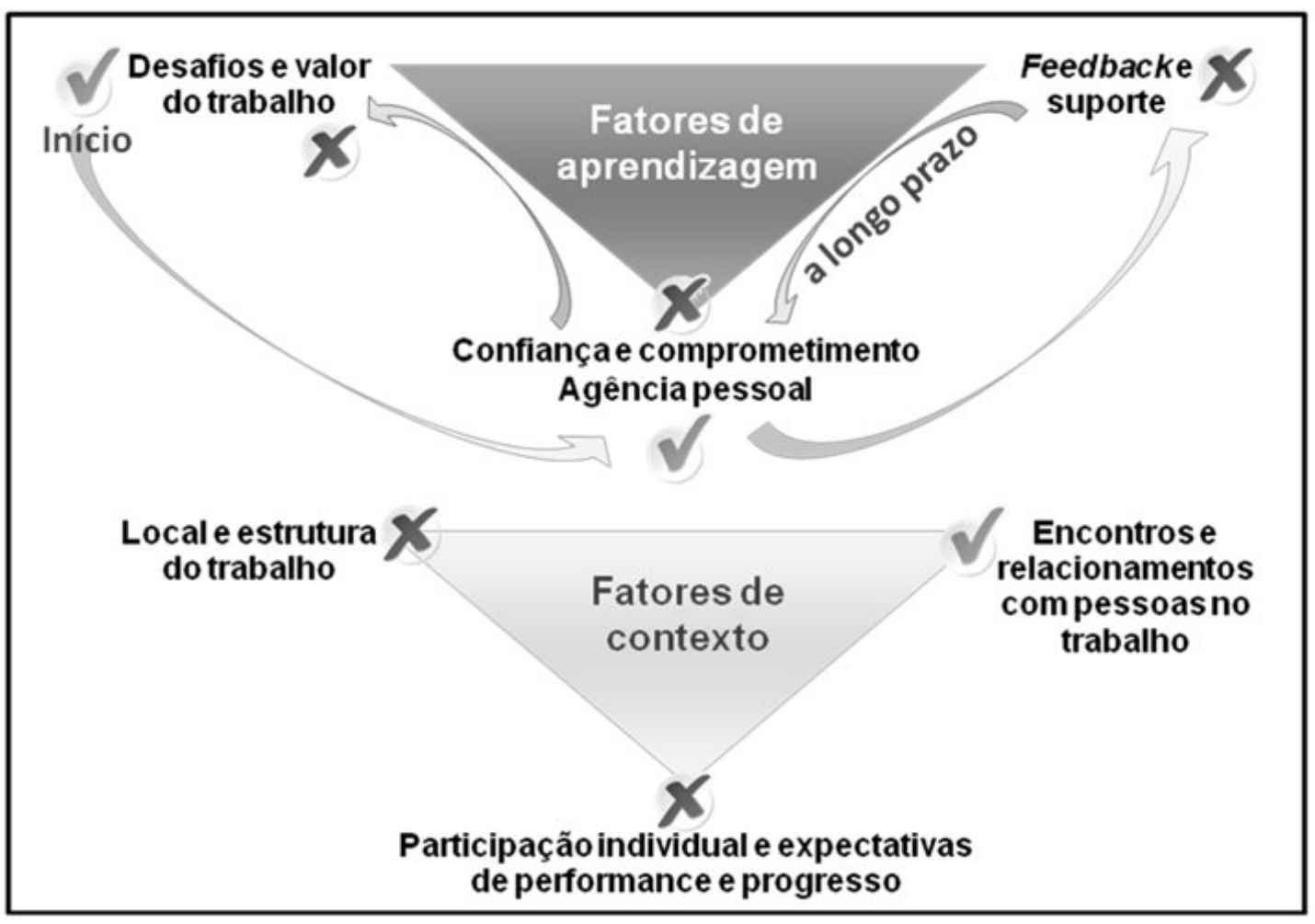

Fonte: elaborado pelos autores a partir de dados de pesquisa (2014) e de acordo com o modelo dos 2 triângulos de Eraut (2004, p.269).

A diversidade de cenários e fatores que influencia o ambiente da faculdade, como a cultura organizacional e a estrutura física, faz com que os desafios no trabalho sejam maximizados, positiva e negativamente (Figura 4 - triângulo inferior). Porém, os técnicos-administrativos avaliam como favorável a qualidade de seus relacionamentos no contexto do trabalho, embora ainda não estejam num padrão ideal de solidariedade, companheirismo, imparcialidade, impessoalidade e profissionalismo. Cenário que tende a mudar, segundo os funcionários, com a renovação do quadro funcional. Quanto aos relacionamentos pessoais no local de trabalho, eles afetam tanto o nível de desafio do trabalho quanto as oportunidades de encontrar, observar e trabalhar ao lado de pessoas que têm mais ou diferentes conhecimentos, de receber feedback ou dar suporte e conselhos para a aprendizagem (ERAUT, 2004). Quanto às expectativas de melhor desempenho e progresso, elas parecem ser precárias no ambiente de trabalho estudado, haja vista a forte presença de fatores políticos e poder na definição de cargos de confiança. A intersecção dos aspectos físicos, culturais e sociais do trabalho na faculdade reflete 
a interação próxima entre esses elementos. Concluise, portanto, que um progresso na interação desses elementos com os servidores produziria melhores resultados e promoveria a AI no local de trabalho estudado.

Os resultados deste estudo estão em consonância com vários pontos encontrados na revisão de literatura das pesquisas nacionais. A natureza descritiva, cujo foco de investigação está direcionado a identificar e compreender os processos de aprendizagem informal, foi adotada pela maioria dos estudos. No entanto, o estudo aqui apresentado, ao focar tais processos dentro de um determinado contexto social, evidenciando o papel das interações sociais no provimento da aprendizagem de indivíduos que não ocupam a função gerencial, proporcionou um diferencial em relação aos estudos anteriores que exploraram o tema. A perspectiva teórica utilizada foi a psicológica, na vertente construção social (DEFILLIPPI; ORNSTEIN, 2003), apoiando-se, especialmente, nos estudos teóricos e de campo produzidos por Bente Elkjaer e colaboradores. No caso dos estudos nacionais anteriores, ressalta-se que eles, embora estejam assentados na noção de aprendizagem pela experiência e na ação, inspiramse na noção de aprendizagem experiencial trazida por Kolb (1984), que estuda a aprendizagem em indivíduos adultos no nível individual, e no conceito de aprendizagem organizacional desenvolvido por Argyris e Schön (1978). Quanto aos objetivos da pesquisa aqui desenvolvida, eles foram respondidos por meio de uma metodologia qualitativa, calcada nos pressupostos do paradigma interpretacionista, seguindo certa preferência já identificada em outros estudos nacionais (REATTO; GODOY, 2015). Porém, o contexto de estudo foi o setor público, em específico, uma universidade, ambiente ainda não explorado na literatura anteriormente revisada.

Espera-se que este estudo tenha contribuído na organização de um modelo explicativo da dinâmica da aprendizagem de indivíduos que não ocupam a função gerencial, evidenciando o papel das interações sociais dentro de um determinado contexto social. Neste sentido, acredita-se que as lentes teóricas aqui articuladas - envolvendo a teoria pragmática da aprendizagem de Bente Elkjaer e colaboradores e os autores do campo $\mathrm{da}$ aprendizagem informal - foram fundamentais na interpretação dos dados encontrados no campo.

Como agenda de pesquisa, sugerem-se estudos que expliquem os microprocessos de aprendizagem formal e informal em contextos específicos, como organizações públicas, em diversas áreas de atuação como educação e saúde. A relação entre novatos e experientes pode ser amplamente estudada ao comparar em que medida a socialização (aprendizagem) institucionalizada ou a automotivada apoia ou suprime os processos de aprendizagem informal. Podem ser incluídos fatores como emoções, poder, políticas e liderança e suas interferências na aprendizagem numa organização pública, ratificando a ausência desses aspectos nos estudos nacionais e internacionais que focam esse segmento (RASHMAN et al., 2009). Além disso, o aprofundamento de como as diversas combinações dos fatores de contextos identificados neste estudo afetam a aprendizagem informal.

\section{Referências}

ADLER, P. S.; BORYS, B. Two types of burocracy: enabling and coercitive. Administrative Science Quartely, v. 41, p. 61-89, 1996.

ANTONELLO, Claudia S. Aprendizagem organizacional e as raízes de sua polissemia. In: ANTONELLO, Claudia. S.; GODOY, Arilda S. (org.) Aprendizagem organizacional no Brasil. Porto Alegre: Bookman, 2011. p.31-50.

ARGYRIS, C.; SCHÖN, D.A. Organizational Learning: a theory of action perspective. Reading, Massachusetts: Addison-Wesley, 1978.

ASHFORTH, Blake E.; SLUSS, David M.; SAKS, Alan M. Socializatins tatics, proactive behavior, and newcomer learning: integrating socialization models. Journal of Vocational Behavior, v. 70, p. 447-462, 2007.

BENOZZO, Angelo; COLLEY, Helen. Emotion and learning in the workplace: critical perspectives.

Journal of Workplace Learning, v. 24, n. 5, p.304316, 2012.

BILLETT, Stephen. Learning throgh work: workplace affordances and individual engagement. Journal of Workplace Learning, v. 13, n. 5, p. 209214, 2001.

. Emerging Perspectives on Workplace

Learning. In: BILLET'T, Stephen; HARTEIS, Christian; ETELÄPELTO, Anneli. Emerging Perspectives of Workplace Learning. Rotterdam: Sense Publishers, 2008. p.1-15. 
BOUD, David; GARRICK, John. Understandings of workplace learning. In: GARRICK, John. Informal Learning in the Workplace: Unmasking Human Resource Development. London: Routledge, 1998. p.1-11.

BRANDI, Ulrik; ELKJAER, Bente. Organizational Learning Viewed from a Social Learning Perspective. In: EASTERBY-SMITH, Mark; LYLES, Marjorie A. Handbook of Organizational Learning and Knowledge Management. New York City: Wiley Publication, 2011. p.23-38.

CONLON, T. J. A review of informal learning literature, theory and implications for practice in developing global professional competence. Journal of European Industrial Training, v. 28 n. 2-4, p. 283-295, 2004.

CRANT, J. M. Proactive behavior in Organizations. Journal of Management, v. 26, n. 3, p. 435-462, 2000 .

CUNHA, Miguel Pina. The times they are a-changin': A sociedade organizacional à entrada do século XXI. In: ANTONELLO, C. S.; GODOY, A. S. (org.) Aprendizagem organizacional no Brasil. Porto Alegre: Bookman, 2011. p. 11-25.

CUNNINGHAM, John; HILLIER, Emilie.

Informal learning in the workplace: key activities and processes. Education and Training, v. 55, n. 1, p.3751, 2013.

DEFILLIPPI, R.; ORNSTEIN, S. Psychological perspectives underlying theories of organizational learning. In: EASTERBY-SMITH, M.; LYLES, M. A. (Ed.). Handbook of organizational learning and knowledge management. London: Blackwell Publishing, 2003. p. 19-37.

ELKJAER, Bente. Em busca de uma teoria de aprendizagem social. In: EASTERBY-SMITH, Mark; BURGOYNE, John; ARAUJO, Luis.

Aprendizagem organizacional e organização de aprendizagem: desenvolvimento na teoria e na prática. São Paulo: Atlas, 2001. p.100-116.

Organizational Learning: The 'Third

Way'. Management Learning, v. 35, n. 4, p.419-434, 2004.

; HUYSMAN, Marleen. Social Worlds

Theory and the power of tension. In: BARRY, David. The Sage Handbook of New Approaches in Management and Organization. London: SAGE, p.170-177, 2008.

Pragmatismo: Uma Teoria da

Aprendizagem para o Futuro. In: ILLERIS, Knud. Teorias Contemporâneas da Aprendizagem. Porto Alegre: Penso, 2013. p.91-108.

ERAUT, Michael. Informal learning in the workplace. Studies in Continuing Education, v. 26, n. 2, p.247-273, 2004.

Informal learning in the workplace:

evidence on the real value of work-based learning (WBL). Development and Learning in Organizations, v. 25, n. 5, p.8-12, 2011.

FLICK, U. Desenho da Pesquisa Qualitativa. Porto Alegre: Bookman Artmed, 2009.

FLORES, Javier Gil. Análisis de datos cualitativos: aplicaciones a la investigación educativa.

Barcelona: PPU, 1994. p.7-107.

GARRICK, John. Informal Learning in the

Workplace: Unmasking Human Resource

Development. London: Routledge, 1998.

GERBER, Rod. Learning and Knowing in

Workplaces: how do people learn in their work. In: CASTLETON, Geraldine; GERBER, Rod; PILLAY, Hitendra. Improving workplace learning: emerging international perspectives. New York: Nova Science Publishers, 2006. p.35-45.

HAGER, Paul. Informal learning: everyday living. In: JARVIS, Peter; WATTS, Michael (org.) The Routledge International Handbook of Learning. USA: Routledge, 2012. p.207-215.

HALL, Richard H. Organizações: estrutura, processos e resultados. 8 ed. São Paulo: Pearson Prentice-Hall, 2004.

JACOBS, Ronald L.; PARK, Yoonhee. A Proposed Conceptual Framework of Workplace Learning: Implications for Theory Development and Research in Human Resource Development. Human Resource Development Review, v. 8, n. 2, p.133-150, 2013.

KOLB, D. A. Experimental learning: experience as the source of learning. New Jersey: Prentice-Hall, 1984.

KVALE, Steinar. The social construction of validity. Qualitative Inquiry, v. 1, p.19-40, 1995. 
LE CLUS, Megan A. Informal Learning in the workplace: a review of the literature. Australian Journal of Adult Learning, v. 51, n. 2, p.355-373, 2011.

LIVINGSTONE, David W. Exploring the icebergs of adult learning: findings of the first Canadian Survey of Informal Learning Practices. Centre for the Study of Education and Work, OISE/University of Toronto. NALL Working Paper, v. 10, 2000. Disponível em: <http://hdl.handle.net/1807/2724>. Acesso em: 19 mai. 2014.

MAHLER, J. Influences of organizational culture on learning in public agencies. Journal of Public Administration Research and Theory, v. 4, p. 519540, 1997.

MALCOLM, Janice; HODKINSON, Phil; COLLEY, Helen. The interrelationships between informal and formal learning. Journal of Workplace Learning, v.15, n. 7/8, p. 313-318. 2003.

MARSICK, Victoria J.; WATKINS, Karen E. Informal and Incidental Learning. New Directions for Adult and Continuing Education, v. 89, p.25-34, 2001.

; YATES, Jennifer L. Informal Learning and Complex Problem Solving of Radiologic Technologists Transitioning to the Workplace. In: HOU, Huei-Tse. New Research on Knowledge Management Applications and Lesson Learned, Croatia: InTech. 2012. p.171-194.

MERRIAN, Sharan B. Qualitative research and case study applications in education. San Francisco: JosseyBass, 1998.

MORAN, E. T; VOLKWEIN, J. F. The cultural approach to the formation of organizational climate. Human Relations, v. 41, n. 1, p. 19-48, 1992.

ONWUEGBUZIE, Anthony J.; LEECH, Nancy. Validity and Qualitative Research: An Oxymoron? Qualitative \& Quantitative Research, v. 41, p.233249, 2006.

PARKER, S. K.; SPRIGG, C. A. Minimizing Strain and Maximizing Learning: the role of job demands, job control, and proactive personality. Journal of Applied Psychology, v. 84, n. 6, p. 925-939, 1999.

PUENTE-PALACIOS, K. E. Abordagens teóricas e dimensões empíricas do conceito de clima organizacional. Revista de Administração, v. 37, n. 3, p. 96-104, 2002.

RASHMAN, Lyndsay; WITHERS, Erin; HARTLEY, Jean. Organizational learning and knowledge in public service organizations: A systematic review of the literature. International Journal of Management Reviews, v. 11, n. 4, p.463-494, 2009.

REATTO, Diogo; GODOY, Arilda Schmidt. A produção sobre Aprendizagem Informal nas organizações no Brasil: mapeando o terreno e rastreando possibilidades futuras. Revista Eletrônica de Administração, v. 21, n. 1, p. 57-88, mar. 2015.

SIMPSON, Barbara; MARSHALL, Nick. The Mutuality of Emotions and Learning in Organizations. Journal of Management Inquiry, v. 19, n. 4, p.351-365, 2010.

SONNENTAG, S. Recovery, Work Engagement, and Proactive Behavior: A New Look at the Interface Between Nonwork and Work. Journal of Applied Psychology, v. 88, n. 3, p. 518-528, 2003.

VINCE, R.; SALEEM, T. The Impact of Caution and Blame on Organizational Learning. Management Learning, v. 35, n. 2, p. 133-154, 2004. 